\title{
Third-year medical students' and clinical teachers' perceptions of formative assessment feedback in the simulated clinical setting
}

\author{
R M Abraham, MBBS, PGDip (Anaesthesia), PGDip (Public Health), MMedSc; V S Singaram, BMedSc, MMedSc, PhD
}

Clinical and Professional Practice, School of Clinical Medicine, College of Health Sciences, University of KwaZulu-Natal, Durban, South Africa

Corresponding author: R M Abraham (abrahamr@ukzn.ac.za)

Background. Clinical skills training in the clinical skills laboratory (CSL) environment forms an important part of the undergraduate medical curriculum. These skills are better demonstrated than described. A lack of direct observation and feedback given to medical students performing these skills has been reported. Without feedback, errors are uncorrected, good performance is not reinforced and clinical competence is minimally achieved. Objectives. To explore the perceptions of 3rd-year medical students and their clinical teachers about formative clinical assessment feedback in the CSL setting.

Methods. Questionnaires with open- and closed-ended questions were administered to 3rd-year medical students and their clinical skills teachers. Quantitative data were statistically analysed while qualitative data were thematically analysed.

Results. Five clinical teachers and 183 medical students participated. Average scores for the items varied between 1.87 and 5.00 (1: negative to 5: positive). The majority of students reported that feedback informed them of their competence level and learning needs, and motivated them to improve their skills and participation in patient-centred learning activities. Teachers believed that they provided sufficient and balanced feedback. Some students were concerned about the lack of standardised and structured assessment criteria and variation in teacher feedback. No statistical difference $(p<0.05)$ was found between the mean item ratings based on demographic and academic background.

Conclusion. Most teachers and students were satisfied with the feedback given and received, respectively. Structured and balanced criterion-referenced feedback processes, together with feedback training workshops for staff and students, are recommended to enhance feedback practice quality in the CSL. Limited clinical staff in the CSL was noted as a concern.

Afr J Health Professions Educ 2016;8(1 Suppl 1):121-125. DOI:10.7196/AJHPE.2016.v8i1.769

A key component of undergraduate medical education is feedback, which is considered the 'lifeblood of learning. ${ }^{[1]}$ Several definitions for feedback exist, but all suggest that feedback is an interactive process with the objective of giving students constructive input into their work. ${ }^{[2]}$ Feedback in the context of behavioural science is defined as the 'provision of information about the gap between the actual level and the reference level of learning that is used to alter the gap in some way. ${ }^{\left[{ }^{[3]}\right.}$ In medical education, feedback is defined as 'specific information about the comparison between trainees' observed performance and a standard, given with the intent to improve the trainee's performance. ${ }^{[4]}$

Feedback can be either formative or summative. Formative feedback in clinical assessment may occur during the theme/module or clinical placement. The objective here is to enhance students' learning ability by informing them of the strong and weak aspects of their clinical performance, and providing suggestions for improvement in preparation for their summative examination. It does not include the rating of clinical skills performance but intends to shape the students' responses to the task being worked on. Summative feedback takes place at the end of a theme/module to determine whether or not overall goals have been achieved and includes explicit feedback with rating of clinical skills performance. It may help to shape the next performance or task but is often received too late to have an effect on the task being evaluated. ${ }^{[5]}$

Formative assessment, through the provision of feedback and debriefing in the simulated clinical setting, is important to support student learning and clinical skills development. Feedback is considered effective when it is: provided soon after task performance; is presented in a manner sensitive to students' learning style; clearly identifies strengths and weaknesses; includes suggestions for improvement; and is constructive, motivating and able to 'feed-forward. ${ }^{[6]}$ Students are aware of its importance in improving learning outcomes and value a balanced and structured feedback approach as effective to meet individual needs. ${ }^{[7]}$ However, concerns about the quality of feedback received by medical students have been highlighted. ${ }^{[8]}$

Clinical skills laboratories (CSLs) are educational facilities that provide medical students with opportunities during the preclinical years to learn and practise clinical skills before using them in real clinical settings. Patient history-taking, performing a physical examination and then analysing and presenting this information involve psychomotor and cognitive skills, as well as behaviour acquired through repetitive and systematic training, and depends upon effective teaching, assessment and feedback ${ }^{[9]}$ in the CSL setting. These skills are better demonstrated than described. Unfortunately, a widely reported deficiency is the lack of dynamic assessment, which involves direct observation and immediate feedback given to medical students' performing these skills. ${ }^{[10]}$ Without feedback on observation, errors go uncorrected, good performance is not reinforced and clinical competence is achieved only minimally. As evidenced from empirical research, students need adequate motivation and belief in their abilities to be able to satisfactorily decode feedback messages to self-regulate their clinical performance. ${ }^{[11]}$

The importance of feedback is also widely acknowledged by clinical teachers. Although they believe they give regular and sufficient feedback, this is often not the perception of learners. ${ }^{[8]}$ In a study conducted to assess the students' voice, students rated assessment feedback as an aspect in need of improvement across 14 universities in Australia. ${ }^{[12]}$ Even though giving feedback to learners on their clinical performance has been identified as 
a major approach to academic teaching and learning in clinical education, it needs to be monitored. ${ }^{[8]}$ The objective of this study was to survey medical students' and clinical teachers' perceptions of formative assessment feedback on direct observation of clinical examination skills performed in the CSL.

\section{Method \\ Context}

The Nelson R Mandela School of Medicine (NRMSM) at the University of KwaZulu-Natal (UKZN), Durban, South Africa has adopted a 6-year hybrid problem-based learning (PBL) medical curriculum. Clinical skills teaching forms a part of each of the theme-based PBL modules during the first three preclinical years taught in the medical school CSL, using simulated patients. The clinical skills mini-logbook formative assessment session occurs before the summative assessments at the end of each 6- to 8-week theme-based module. During the formative assessment sessions, each student is given 8 minutes to systematically demonstrate examination skills on a simulated patient. The teacher observes each student and rates the performance in the mini-logbook, based on the minimum requirements for the skill to be deemed satisfactory. Performances are rated as 'inadequate, 'satisfactory' or 'exceeded expectation' and verbal and written feedback are provided.

\section{Study design}

This mixed methods observational study was conducted with the 2014 cohort of 3rd-year medical students and their clinical skills teachers at the NRMSM. Ethical approval was granted by the UKZN Humanities and Social Sciences Research Ethics Committee (HSS/0084/014M). Third-year medical students $(N=183)$ and clinical teachers $(N=5)$ consented to completing the questionnaires. The research design involved mixing both qualitative and quantitative research data to provide a more comprehensive understanding of the perceptions of both the students and teachers.

\section{Instrument}

Two questionnaires, consisting of closed- and open-ended questions, were designed. One questionnaire was designed to explore the teachers' perceptions of the feedback. The other questionnaire explored students' responses to the mini-logbook formative assessment feedback received with regard to the value of feedback, preferences for feedback and suggestions to improve feedback. Each instrument consisted of the following components, which formed the different sections of the questionnaire: (i) demographic data; (ii) perceptions of feedback; (iii) value of feedback; (iv) preferences for feedback; and (v) suggestions for feedback. Sections (ii), (iii) and (iv) included closed questions that required students and clinical teachers to indicate their level of agreement with a series of statements on a 5-point Likert scale, ranging from 'strongly disagree' to 'strongly agree'. There were two open-ended questions on the general perceptions of feedback (section (iii)) and suggestions to improve it (section $(v)$ ). Minor modifications were made after questionnaires were piloted.

\section{Data analysis}

Quantitative data were analysed statistically using the Statistical Package for the Social Sciences (SPSS) (version 21) (IBM, USA) and reported anonymously. Student independent $t$-tests and analysis of variance (ANOVA) statistical tests were employed to ascertain specific age, gender, language, enrolment status and academic performance differences between the demographic groups. Confidence intervals (CIs) were set at $95 \%$ and statistical significance at $p<0.05$. The qualitative data were read and reread for familiarity with what it entailed, paying specific attention to patterns that occurred. The pattern of responses was used to identify emergent themes, with consensus from both authors. The student and teacher responses were then clustered according to the emergent themes and categorised according to the degree of support that a particular response represented in terms of the total sample. The qualitative data gathered from the students' and clinical teachers' responses to the open-ended questions were thematically analysed and will be reported in more detail in a follow-up study ${ }^{[13]}$ Specific quotations were selected to support or extend the quantitative data that are the focus of this article.

\section{Results}

The student sample consisted of 115 (68\%) females. The majority (96\%) were between 18 and 25 years of age. The teachers consisted of $1(20 \%)$ female and $4(80 \%)$ male clinicians. The students and teachers came from diverse multicultural, language and academic backgrounds.

\section{Students' responses to feedback received}

Illustrated in Table 1, most students believed that receiving feedback had a positive effect on their learning by informing them of what was needed to improve their performance (94\%), explaining the performance rating received $(90 \%)$ and providing an evaluation of their strengths and weaknesses in clinical skills (96\%). They also appreciated feedback as it informed them of the teachers' expectations with regard to the skil

Table 1. Clinical skills logbook assessment feedback: impact of feedback on academic performance $(N=183)$

\begin{tabular}{llll}
\hline & \multicolumn{3}{c}{ Response } \\
\cline { 2 - 4 } Statement & $\begin{array}{l}\text { Positive } \\
\text { response, \% }\end{array}$ & $\begin{array}{l}\text { Neutral } \\
\text { response, \% }\end{array}$ & $\begin{array}{l}\text { Negative } \\
\text { response, \% }\end{array}$ \\
\hline $\begin{array}{l}\text { Feedback informs me what I need to do to improve my } \\
\text { performance in clinical skills }\end{array}$ & 94 & 4 & 1 \\
$\begin{array}{l}\text { Feedback explains the performance rating I received in } \\
\text { the logbook }\end{array}$ & 90 & 9 & 1 \\
$\begin{array}{l}\text { Feedback is an evaluation of my strengths and } \\
\text { weaknesses in the skill performed }\end{array}$ & 96 & 3 & 1 \\
$\begin{array}{l}\text { Feedback informs me what the expectations of the } \\
\text { lecturer/teacher are regarding clinical skills performance }\end{array}$ & 93 & 5 & 2 \\
$\begin{array}{l}\text { I use feedback to try to improve my performance } \\
\text { in future logbook assessments and end-of-semester } \\
\text { objective structured clinical examinations }\end{array}$ & 93 & 6 & 2 \\
$\begin{array}{l}\text { Feedback is only useful when I receive a bad } \\
\text { performance rating in the logbook }\end{array}$ & 12 & 5 & 82 \\
$\begin{array}{l}\text { Feedback is only useful when it is positive } \\
\text { Getting a performance rating is more important to my } \\
\text { learning than feedback }\end{array}$ & 23 & 7 & 86 \\
\end{tabular}


performed (93\%) and was useful and relevant to their goals as a student to feed-forward (93\%):

'I really appreciated the fact that we have logbook sessions before the actual exam ... It helps me to see my weak points.'

Although feedback was valued, the students did not think feedback was useful if it only reported a bad performance $(82 \%)$ or a good performance $(86 \%)$. They were more likely to value balanced feedback with positive reinforcement and constructive criticism indicative of an understanding of their performance:

'Teachers must give us feedback that is truly indicative of our performance. They must not focus only on the wrong things but also explain how we can improve the things that we did well.'

Students reported that they valued the feedback received (99\%) and always ensured they read the feedback provided in the logbook (98\%) (Table 2). They believed that they deserved to receive feedback, especially after putting effort into practising clinical skills (96\%), as it encouraged (92\%) and motivated them to study (93\%). Students felt that their teachers' feedback was a demonstration of them caring about a student's work (78\%).

They suggested ways to improve their feedback experience and requested feedback as a tool to gauge their knowledge in summative assessments:

'We don't receive feedback for our [objective structured clinical examinations] OSCEs. I believe to improve we should be given this feedback as it is an indication of how much more work you need to put towards your clinical skills.

An important issue raised was teacher variability when delivering feedback (60\%) and the need for more clarity when providing feedback. The criteria with which feedback was provided were of concern. Students linked feedback variation to lack of use of standardised and structured assessment criteria by the teachers. When prompted for recommendations for improving clinical skills logbook assessment feedback they suggested standardisation:

'Logbook sessions are useful in assessing our skills. However, I feel that teachers should use the same methods of testing to make things fair for all students. Assessment criteria must be available to students as a form of learning objectives and goals?

Students were satisfied with the timely delivery of feedback (85\%). They valued some general feedback (51\%) as it gave them an idea about

Table 2. Clinical skills logbook assessment feedback: impact of feedback on personal motivation to learn $(N=183)$

\begin{tabular}{|c|c|c|c|}
\hline \multirow[b]{2}{*}{ Statement } & \multicolumn{3}{|c|}{ Response } \\
\hline & $\begin{array}{l}\text { Positive } \\
\text { response, \% }\end{array}$ & $\begin{array}{l}\text { Neutral } \\
\text { response, \% }\end{array}$ & $\begin{array}{l}\text { Negative } \\
\text { response, \% }\end{array}$ \\
\hline Feedback is important to me & 99 & 1 & 0 \\
\hline I always read the feedback on my logbook & 98 & 1 & 1 \\
\hline $\begin{array}{l}\text { I deserve feedback when I put a concerted effort into } \\
\text { practising my clinical skills }\end{array}$ & 96 & 3 & 1 \\
\hline When I receive substantial feedback I feel encouraged & 92 & 7 & 1 \\
\hline $\begin{array}{l}\text { Teachers who provide feedback care about what the } \\
\text { students generally think }\end{array}$ & 78 & 15 & 6 \\
\hline Feedback motivates me to study & 93 & 7 & 0 \\
\hline $\begin{array}{l}\text { When I don't receive feedback I feel that the teacher does } \\
\text { not respect me }\end{array}$ & 44 & 34 & 22 \\
\hline $\begin{array}{l}\text { All the clinical skills teachers follow a similar style and } \\
\text { criteria of providing feedback }\end{array}$ & 16 & 24 & 60 \\
\hline $\begin{array}{l}\text { An important part of learning is being able to discuss the } \\
\text { subject with my teacher }\end{array}$ & 92 & 7 & 1 \\
\hline I learn more when my teacher focuses on what I did wrong & 63 & 15 & 22 \\
\hline
\end{tabular}

Table 3. Clinical skills logbook assessment feedback: references for feedback $(N=183)$

\begin{tabular}{|c|c|c|c|}
\hline \multirow[b]{2}{*}{ Statement } & \multicolumn{3}{|c|}{ Response } \\
\hline & $\begin{array}{l}\text { Positive } \\
\text { response, \% }\end{array}$ & $\begin{array}{l}\text { Neutral } \\
\text { response, \% }\end{array}$ & $\begin{array}{l}\text { Negative } \\
\text { response, \% }\end{array}$ \\
\hline $\begin{array}{l}\text { Feedback on clinical skills logbook assessments is } \\
\text { generally provided immediately }\end{array}$ & 85 & 5 & 10 \\
\hline $\begin{array}{l}\text { General feedback provided in class helps me learn } \\
\text { independently }\end{array}$ & 62 & 23 & 15 \\
\hline $\begin{array}{l}\text { Individual feedback is better because I can clarify any } \\
\text { issues with the teacher or lecturer }\end{array}$ & 88 & 8 & 4 \\
\hline Verbal feedback is easier to understand & 76 & 19 & 6 \\
\hline $\begin{array}{l}\text { Specific feedback is better because it helps me understand } \\
\text { what I did right and wrong in the logbook session }\end{array}$ & 96 & 3 & 2 \\
\hline It is boring when lecturers provide general feedback to the class & 27 & 39 & 34 \\
\hline I prefer general feedback in class because it is not personal & 8 & 26 & 66 \\
\hline $\begin{array}{l}\text { I prefer verbal feedback because I can communicate with } \\
\text { the teacher and clarify information }\end{array}$ & 75 & 21 & 4 \\
\hline $\begin{array}{l}\text { Group feedback is best because I can see where other } \\
\text { students have experienced similar problems }\end{array}$ & 51 & 25 & 24 \\
\hline $\begin{array}{l}\text { Teachers' written comments are often difficult to read } \\
\text { and inadequately explained }\end{array}$ & 21 & 27 & 53 \\
\hline Written feedback is better because I can refer to it much later & 69 & 19 & 12 \\
\hline
\end{tabular}

whether other students in the class experienced similar problems (Table 3). One suggestion made was the need for the following:

'... a little more group feedback to judge where

I am in the class and whether or not I am putting enough effort into my learning.'
The students acknowledged individual feedback (88\%) as more personal and fitting for clarifying issues with teachers as an important part of their learning:

'It is always better for one-on-one feedback that focuses on individual needs and allows students 
to interact with the facilitator easily, ask questions and receive clarification when necessary'

The students preferred verbal feedback (75\%) specific to their work, including both positives and negatives in the skill demonstrated:

'More emphasis on verbal individual feedback for me ... because it focuses specifically on my performance and accounts not only for the things I got wrong but the things I got right and what I need to improve on.

\section{Clinical teachers' perceptions of giving feedback}

As illustrated in Table 4, teachers were comfortable with providing feedback, and agreed that effective performance feedback improved students' learning and required their engagement with and necessary skill in the feedback provision process. They all reported providing individual and verbal feedback, while some amount of written and group feedback was also given. Three teachers indicated that the setting in which feedback was provided in the CSL was private; one was neutral regarding this, while another did not think the setting was private enough. Three teachers provided feedback that reflects more general information on the students' performance. Three teachers allowed the students to self-assess and reflect on their performance to confirm if they agreed or disagreed with the feedback information provided.

Most teachers disagreed that the culture and language background of students determined the feedback they give:

'I do not really take account of culture and background because I am only focused on the topic, the technique and documentation of clinical skills.'

However, one teacher considered language and culture to be an important factor while providing feedback:

'For second-language students the delivery of feedback is important. Also, from a cultural perspective students may see me as a figure of authority and misconstrue my feedback as "scolding".

The majority of teachers felt that staff development is crucial for increasing teachers' confidence and skill in this area of giving feedback:

'A workshop on feedback in clinical skills is very important. It will allow all teachers to harmonise the way they have to improve and deliver the feedback.

Table 4. Clinical teachers' perceptions of feedback provided during a logbook session $(N=5)$

\begin{tabular}{|c|c|c|c|}
\hline \multirow[b]{2}{*}{ Statement } & \multicolumn{3}{|c|}{ Response } \\
\hline & $\begin{array}{l}\text { Positive } \\
\text { response, \% }\end{array}$ & $\begin{array}{l}\text { Neutral } \\
\text { response, \% }\end{array}$ & $\begin{array}{l}\text { Negative } \\
\text { response, \% }\end{array}$ \\
\hline $\begin{array}{l}\text { Provision of effective performance feedback to medical } \\
\text { students improves learning outcomes }\end{array}$ & 100 & 0 & 0 \\
\hline $\begin{array}{l}\text { Provision of clearly effective feedback would require } \\
\text { engagement and skill }\end{array}$ & 100 & 0 & 0 \\
\hline $\begin{array}{l}\text { I often provide the following types of feedback to my } \\
\text { students (verbal) }\end{array}$ & 100 & 0 & 0 \\
\hline $\begin{array}{l}\text { I often provide the following types of feedback to my } \\
\text { students (written) }\end{array}$ & 40 & 0 & 60 \\
\hline $\begin{array}{l}\text { I often provide the following types of feedback to my } \\
\text { students (group) }\end{array}$ & 60 & 0 & 40 \\
\hline $\begin{array}{l}\text { I often provide the following types of feedback to my } \\
\text { students (individual) }\end{array}$ & 100 & 0 & 0 \\
\hline $\begin{array}{l}\text { The students are aware that they would be receiving } \\
\text { feedback after the clinical performance }\end{array}$ & 100 & 0 & 0 \\
\hline Feedback is often provided in a confidential setting & 60 & 20 & 20 \\
\hline $\begin{array}{l}\text { The feedback I provide only reflects what the student did } \\
\text { satisfactorily }\end{array}$ & 20 & 0 & 80 \\
\hline $\begin{array}{l}\text { The feedback I provide only reflects what the student did } \\
\text { unsatisfactorily }\end{array}$ & 40 & 0 & 60 \\
\hline $\begin{array}{l}\text { The feedback I provide is usually a balance between what } \\
\text { the student did well and what areas require improvement }\end{array}$ & 100 & 0 & 0 \\
\hline $\begin{array}{l}\text { The feedback I provide reflects more specific } \\
\text { information about the student's clinical performance }\end{array}$ & 100 & 0 & 0 \\
\hline $\begin{array}{l}\text { The feedback I provide reflects more general aspects of } \\
\text { the student's clinical performance }\end{array}$ & 60 & 20 & 20 \\
\hline $\begin{array}{l}\text { Immediately after providing the feedback I would allow } \\
\text { the students to self-assess and reflect on their performance } \\
\text { to confirm if they agree or disagree with the feedback }\end{array}$ & 60 & 20 & 20 \\
\hline I am comfortable providing feedback to students & 100 & 0 & 0 \\
\hline $\begin{array}{l}\text { The culture and language background of the students is } \\
\text { an important factor when giving feedback }\end{array}$ & 60 & 20 & 20 \\
\hline $\begin{array}{l}\text { I feel there should be formal training to improve and } \\
\text { enhance my feedback skills as an academic }\end{array}$ & 60 & 20 & 20 \\
\hline
\end{tabular}

Teachers also indicated some barriers and suggestions to improve feedback in clinical skills:

'Regular student and staff evaluations and increase time for feedback. These approaches are limited by time and staffing resource constraints.

\section{Discussion}

Lack of effective feedback is considered a serious deficiency in medical education. ${ }^{[7]}$ It is therefore positive to note that the current study found that most students and teachers were satisfied with the mini-logbook formative assessment feedback in the CSL.
Similar to previous studies, students valued the feedback received during clinical skills sessions as most of them requested personalised, frequent, immediate and clear feedback linked to specific learning outcomes as a tool to gauge their knowledge relevant to their goals. ${ }^{[14]}$ They confirmed that receiving timely feedback had a positive effect on their learning and clinical performance and hence their future practice. The students preferred balanced feedback as an evaluation of their strengths and weaknesses essential for their growth as a student, to boost their confidence and self-esteem, to increase their motivation to study and to provide them 
with some direction for learning. This may have a positive effect on their subsequent clinical performance and the development of their clinical competence. ${ }^{[2]}$

Although there were a wide variety of feedback preferences, the medical students who took part in the study preferred personal, individual and verbal feedback. This afforded them an opportunity to communicate with the teacher and clarify information - an important part of learning. ${ }^{[15]}$ Some group feedback was favoured, as it gave students an idea about whether other students in the class experienced similar problems. While some found general comments uninformative, this method of feedback must not be dismissed as students should be able to probe feedback by asking specific questions. ${ }^{[16]}$

The clinical skills teachers in this study all agreed that providing directly observed immediate formative feedback improved students' learning and allowed enough time for students to make changes to their performance before examinations. ${ }^{[17]}$ Some teachers allowed students to reflect on their performance, providing them with insight into the students' ability to self-assess and reflect. ${ }^{[6]}$ Although teachers were aware that providing regular, balanced feedback with clear guidelines for improvement is essential and the teachers believed they provided this most of the time, this is not how the students perceived the situation. One of the reasons that may explain deficiency in the delivery of negative feedback in this setting may be the teachers' desire to avoid upsetting students, leading to 'vanishing feedback' and subsequent avoidance in giving any feedback. Even though cultural and linguistic differences did not seem to influence the feedback process, a concern regarding misconceptions was attributed to different cultural and language backgrounds. Staff development workshops on the provision of negative feedback ${ }^{[18]}$ and diversity training to bridge language and cultural differences is recommended to address these challenges. There were other concerns raised by the clinical teachers with regard to the effective delivery of feedback. These included the challenges of teaching and assessing large groups of students within a short time period in an environment that is not adequately private, as well as limited space and time for recording feedback in the mini-logbook. Moreover, a greater emphasis on assessment, as opposed to giving feedback, was noted, together with a request from teachers for training to enhance their skills in giving feedback. The limited clinical staffing was raised as a barrier to providing effective feedback, highlighting the need for more clinical teachers in the CSL.

Some students commented on teacher variability and inconsistency in the quality of feedback delivered during clinical skills mini-logbook sessions. These findings are similar to those of other studies revealing that learners often do not feel they receive enough feedback and if they do, they feel that the process is not effective most of the time. ${ }^{[7]}$ Students attributed this variability to the lack of standardised and structured feedback assessment criteria. Another reason contributing to the discounting of feedback by the students may be their unfamiliarity with a particular teacher and their assessment style. Connecting with teachers to create a positive and healthy environment will enhance the feedback process and eliminate barriers to the use of feedback as a tool for self-improvement and development. ${ }^{[19]}$ This will further help students recognise areas for clinical skills development by assisting them to self-regulate and self-monitor their learning processes. ${ }^{[20]}$

\section{Conclusion}

The students recognised the transferable value of the learning skills developed as a result of an effective feedback for processing new learning. Hence, they valued the effect of feedback as an instrument to guide and regulate their learning. Based on information from this study on students' varied and inconsistent experiences with receiving feedback, feedback briefing or training sessions, together with the development of an appropriate feedback strategy, are recommended for students and teachers. A structured and balanced criterion-referenced feedback process is also recommended to enhance the consistency of feedback practice and provide fair assessment. Moreover, establishing an instructional system and revising the clinical skills mini-logbook to a more specific criterion-based, standardised and structured feedback instrument, as well as extending it to other clinical disciplines, are suggested.

Further regular evaluation of the feedback process in the CSL would help to maintain and enhance clinical skills core competencies and provide direction to address any deficiencies in the clinical skills teaching programme.

Acknowledgements. This publication was made possible by grant No. R24TW008863 from the Office of the US Global AIDS Coordinator and the US Department of Health and Human Services, National Institutes of Health. Its contents are solely the responsibility of the authors and do not necessarily represent the official views of the US government. The staff and students who participated in the study are also acknowledged.

\section{References}

1. Rowntree D. Assessing Students: How Shall We Know Them? 2nd ed. London: Kogan, 1987:86. [http://dx.doi. org/10.2307/1981340]

2. Fraut M. Feedback Learn Health Soc Care 2006.5(3):111-118. [http///dx doi.org/10.1111/j.1473-6861.2006.00129x ] 3. Ramprasad A. On the definition of feedback. Behav Sci 1983;28(1):4-13. [http://dx.doi.org/10.1002/bs.3830280103] 4. Van de Ridder JM. What is feedback in clinical education? Med Educ 2008;42(2):189-197. [http://dx.doi. Van de Ridder JM. What is feedback in
org/10.1111/j.1365-2923.2007.02973.x]

5. Wiggins G. Feedback: How learning occurs. In: Chaffee EE, ed. Assessing Impact: Evidence and Action. Washington, DC: American Association for Higher Education, 1997:31-39.

6. Hattie JA, Timperley H. The power of feedback. Rev Educ Res 2007;77(1):81-112. [http://dx.doi org/10.3102/003465430298487]

7. Weinstein DF. Feedback in clinical education: Untying the Gordian knot. Acad Med 2015;90(5):559-561. [http:// dx.doi.org/10.1097/acm.0000000000000559]

8. Edgren G, Haffling AC, Jakobsson U, et al. Comparing the educational environment (as measured by DREEM) at two different stages of curriculum reform. Med Teach 2010;32(6):e233-e238. [http://dx.doi. org/10.3109/01421591003706282]

9. Association of American Medical Colleges. Recommendations for Clinical Skills Curricula for Undergraduate Medical Education. Washington, DC: AAMC, 2005. https://www.aamc.org/download/130608/data/clinicalskills oct09.qxd.pdf.pdf (accessed 22 May 2014)

10. Association of American Medical Colleges. Medical School Graduation Questionnaire. 2012. All School Association of American Medical Colleges. Medical School Graduation Questionnaire. 2012. All School
Summary Report. Washington, DC: AAMC, 2014. https://www.aamc.org/data/gq/allschoolsreports (accessed 17 February 2015)

11. Wright K. Student nurses' perceptions of how they learn drug calculation skills. Nurse Educ Today 2012;32(6):721726. [http://dx.doi.org/10.1016/j.nedt.2011.09.014]

12. Scott G. Assessing the Student Voice: A Higher Education Innovation Program Project. Canberra: Department of Education, Science and Training, 2006:8-10.

3. Krippendorff K. Content Analysis: An Introduction to its Methodology. 2nd ed. Thousand Oaks, CA: Sage Publications, 2004:413. [http://dx.doi.org/10.1177/1094428108324513]

14. Hounsell D. Towards more sustainable feedback to students. In: Boud D, Falchikov N, eds. Rethinking Assessment in Higher Education. London: Routledge, 2007:101-113.

15. Parikh A, McReelis K, Hodges B. Student feedback in problem-based learning: A survey of 103 final year students across five Ontario medical schools. Med Educ 2001;35(7):632-636. [http://dx.doi.org/10.1046/j.13652923.2001.00994.x]

16. Dent J, Harden RM. A Practical Guide for Medical Teachers. 4th ed. New York: Elsevier Health Sciences, 2013:273-275. [http://dx.doi.org/10.1136/pmj.78.916.125]

17. Krackov SK. Expanding the horizon for feedback. Med Teach 2011;33(7):570-575. [http://dx.doi.org/10.3109/0 142159x.2011.617797]

18. Ende J. Feedback in clinical medical education. JAMA 1983;250(6):777-781. [http://dx.doi.org/10.1001/ jama.250.6.777

9. Watling C, Driessen E, van der Vleuten CP, Lingard L. Learning from clinical work: The roles of learning cues and credibility judgements. Med Educ 2012;46(2):192-200. [http://dx.doi.org/10.1111/j.1365-2923.2012.04126.x]

20. Raftery S. Feedback: An essential element of student learning in clinical practice. Nurse Educ Pract 2008;8(6):405411. [http://dx.doi.org/10.1016/j.nepr.2008.02.003] 